\title{
INHALT
}

Geleitwort von Adolf Köberle $\ldots \ldots \ldots \ldots \ldots \ldots \ldots \ldots \ldots$

Einleitung von Reinhard Mumm $\ldots \ldots \ldots \ldots \ldots \ldots \ldots \ldots$

\section{SELBSTZEUGNISSE AUS DEM LEBEN}

Rückblick nach 50 Jahren: Was bleibt? . . . . . . . . . . 14

Michaelsbruderschaft-Rückkehr und Rechenschaft ....... 27

II. ZUM VERSTÅNDNIS DER HEILIGEN SCHRIFT

Drei Stücke aus dem Gottesjahr $1936 \ldots \ldots \ldots \ldots \ldots \ldots \ldots . \ldots 44$

1. Die Einheit der Bibel $\ldots \ldots \ldots \ldots \ldots \ldots \ldots \ldots \ldots \ldots, 44$

2. Die Gleichnisrede $\ldots \ldots \ldots \ldots \ldots \ldots \ldots \ldots \ldots \ldots$

3. Die alte und die neue Schöpfung $\ldots \ldots \ldots \ldots \ldots \ldots \ldots$

Das Kreuz Christi (Drei Vorträge in der Karwoche 1922) . . . . 65

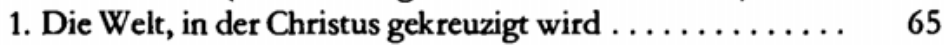

2. Christus, der sich kreuzigen läßt ............ 76

3. Gott, der Christus ans Kreuz gibt $\ldots \ldots \ldots \ldots \ldots \ldots . \ldots 8$

Das Kreuzeszeichen (Vortrag 1974) . . . . . . . . . . 99

1. Joh. 4, 13-16 - Eine biblische Besinnung . . . . . . . 108

Der Heilige Geist tut das Unerwartete . . . . . . . . . 123

III. KIRCHE IN DER ZEIT

Absage an die Götter (Zwei Vorträge 1947) . . . . . . . . 128

1. Die geistige Krisis der Gegenwart $\ldots \ldots \ldots \ldots \ldots \ldots \ldots \quad 128$

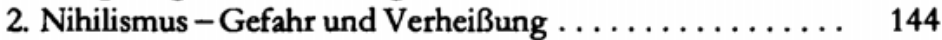

Fragen der Anthroposophie an die Evangelische Kirche ..... 165

Die Frage nach der Einheit der Kirche . . . . . . . . . 193

IV. HILFEN ZUM GLAUBEN UND LEBEN

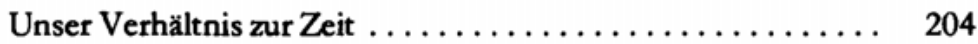

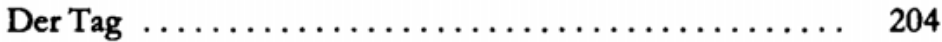

1. Tag und Nacht $\ldots \ldots \ldots \ldots \ldots \ldots \ldots \ldots \ldots \ldots \ldots \ldots$

2. Vom dreifachen Morgen $\ldots \ldots \ldots \ldots \ldots \ldots \ldots \ldots$

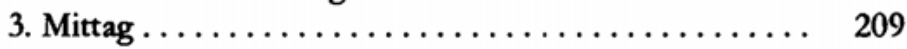

4. Vom Tischgebet $\ldots \ldots \ldots \ldots \ldots \ldots \ldots \ldots \ldots \ldots \ldots \ldots \ldots \ldots$

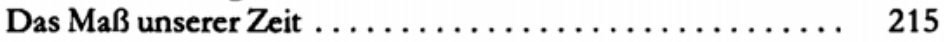

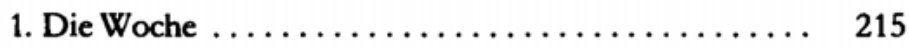

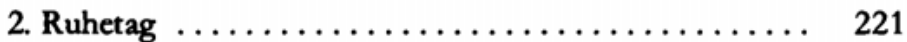

3. Vom Gebet . . . . . . . . . . . . . . . . . . 224 
Gottesdienst und Kirchenjahr. . . . . . . . . . . . . . . 227

1. Unsere Wochensprüche ...................... 227

2. Kirchenschmuck ..................... 232

3. Das Heilige Mahl ..................... 240

Lehre und Erziehung $\ldots \ldots \ldots \ldots \ldots \ldots \ldots \ldots \ldots \ldots \ldots \ldots \ldots \ldots \ldots \ldots$

1. Erziehung aus dem Glauben ................. 247

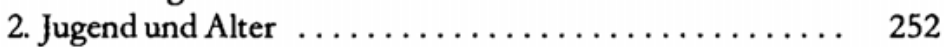

3. Das Märchen vom Storch .................. 258

Der Glaube an den Schöpfer . . . . . . . . . . . . . . . . 262

1. Natur ............................ 262

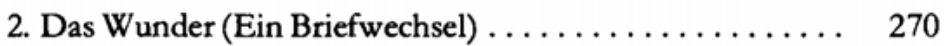

Der Glaube an den Erlöser . . . . . . . . . . . . . . . . . . . . . 279

1. Ich bin ............................ 279

2. Der kommende Herr .................... 287

Der Glaube - Die Kirche und das Ziel der Zeit . . . . . . . . 291

1. Das Geheimnis der Kirche . . . . . . . . . . . . . . . . . . 291

2. Das Ende .............................. 294

Geistliches Leben . . . . . . . . . . . . . . . . . . . . . 297

1. Geistliche Übung . .................... 297

2. Gebete und Betrachtungen ................. 305

4. Bruderschaft ........................... 311

Hilfe im Alltag . ......................... 314

1. Was keine Zeit kostet $\ldots \ldots \ldots \ldots \ldots \ldots \ldots \ldots \ldots \ldots \ldots \ldots \ldots$

2. Die anderen Menschen ................... 322

3. Du sollst nicht schielen ..................... 325

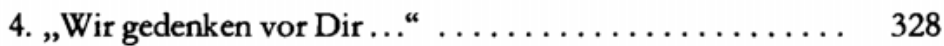

Drei Worte zum Sonntag im Deutschen Fernsehen ....... 331

\section{ZUM ÖFFENTLICHEN LEBEN}

Freiheit und Ordnung $\ldots \ldots \ldots \ldots \ldots \ldots \ldots \ldots \ldots \ldots \ldots \ldots \ldots \ldots, \quad 338$

Macht und Ohnmacht der Ratio im europäischen Erbe ..... 347

Aufstieg und Niedergang der Welt $\ldots \ldots \ldots \ldots \ldots \ldots \ldots, \quad 361$

Wilhelm Stählins Leben in Daten . . . . . . . . . . . . . . . . 371

Handschriftenprobe Wilhelm Stählins . . . . . . . . . . . . 372

Nachweis der Quellen .......................... 374 